\title{
Mechanisms of Enhanced Cholesteryl Ester Transfer from High Density Lipoproteins to Apolipoprotein B-containing Lipoproteins during Alimentary Lipemia
}

Alan Tall, David Sammett, and Esther Granot

Department of Medicine, Columbia University College of Physicians and Surgeons, New York 10032

\begin{abstract}
In vitro lipoprotein lipase enhances the cholesteryl ester transfer protein (CETP)-mediated transfer of cholesteryl esters from high density lipoproteins (HDL) to very low density lipoproteins as a result of lipolysis-induced alterations in lipoprotein lipids that lead to increased binding of CETP. To determine if there are similar changes during alimentary lipemia, we measured the transfer of cholesteryl esters from HDL to apo B-containing lipoproteins in incubated fasting and postprandial plasma. In seven normolipidemic subjects there was 2-3-fold stimulation of cholesteryl ester transfer in alimentary lipemic plasma. Cholesteryl ester transfer was stimulated when either the $d<1.063$ or $d>1.063-\mathrm{g} / \mathrm{ml}$ fraction of lipemic plasma was recombined with its complementary fraction of fasting plasma. To determine the distribution of CETP, plasma was fractionated by agarose chromatography and CETP activity was measured in column fractions in a standardized assay. In fasting plasma, most of the CETP was in smaller HDL, and a variable fraction was nonlipoprotein bound. During lipemia there was increased binding of CETP to larger phospholipid-enriched HDL and in two subjects an increase in CETP in apo B-containing lipoproteins. The total CETP activity of fractions of lipemic plasma was increased 1.11.7-fold compared with fasting plasma. Lipemic CETP activity was also increased when measured in lipoprotein-free fractions after dissociation of CETP from the lipoproteins. When purified CETP was incubated with phospholipid-enriched HDL isolated from alimentary lipemic or phospholipid vesicle-treated plasma, there was increased binding of CETP to the phospholipid-enriched HDL compared with fasting HDL, with a parallel stimulation in CETP activity. Thus, the pronounced stimulation of cholesteryl ester transfer during alimentary lipemia is due to (a) an increased mass of triglyceride-rich acceptor lipoproteins, (b) a redistribution of CETP, especially increased binding to larger phospholipid-enriched HDL, and (c) an increase in total activity of CETP, perhaps due to an increased CETP mass.
\end{abstract}

\section{Introduction}

During incubation of human plasma there is net transfer of cholesteryl esters from high density to less dense lipoproteins, especially to triglyceride-rich particles (1). The significance of the intraplasmic transfer of cholesteryl esters is that it provides a

Address correspondence to Dr. Tall.

Received for publication 25 June 1985 and in revised form $23 \mathrm{De}$ cember 1985 .

J. Clin. Invest.

(c) The American Society for Clinical Investigation, Inc.

0021-9738/86/04/1163/10 $\$ 1.00$

Volume 77, April 1986, 1163-1172 mechanism by which cholesteryl esters formed within high density lipoproteins (HDL) by the action of lecithin:cholesterol acyltransferase (LCAT) ${ }^{1}$ may be redistributed to other lipoproteins (2). The cholesteryl esters transferred to very low density lipoproteins (VLDL) and low density lipoproteins (LDL) are probably largely removed by receptor-mediated uptake in the liver $(3,4)$. Thus, the transfer of cholesteryl esters may function as part of a chain of events involved in centripetal cholesterol transport from peripheral tissues to liver. On the other hand, the accumulation of cholesteryl esters in VLDL or chylomicron remnants may lead to the formation of atherogenic, cholesteryl ester-rich remnant particles (4). The transfer and exchange of cholesteryl esters between plasma lipoproteins are mediated by a plasma cholesteryl ester transfer protein (CETP) (5-11). CETP mediates net transfer of cholesteryl esters from HDL to triglyceride-containing lipoproteins as a result of heteroexchange of cholesteryl esters for triglycerides; when donor and acceptor lipoproteins contain the same triglyceride/cholesteryl ester ratio, exchange rather than net transfer of lipids results (12).

In in vitro experiments, lipoprotein lipase enhances the CETP-mediated transfer of cholesteryl esters from HDL to VLDL (13). Lipolysis-induced alterations of the lipids of VLDL and HDL lead to increased binding of CETP to the lipoproteins, resulting in more efficient cholesteryl ester transfer (14). The important lipid alterations include accumulation of fatty acids in VLDL remnants and in HDL, and enrichment of HDL with phospholipids (14) as a result of the transfer of VLDL surface lipids into HDL during lipolysis (15-18). Since the in vivo transfer of chylomicron phospholipids into HDL results in a similar enrichment of HDL phospholipids $(19,20)$, we hypothesized that alimentary lipemia might be associated with enhancement of CETP activity. We therefore measured the transfer of cholesteryl esters from HDL to the other lipoproteins in incubated plasma obtained from subjects during fasting or after ingestion of a fatty meal. These studies showed a substantial increase in the velocity of cholesteryl ester transfer in lipemic plasma. Further investigations of the mechanism of stimulated cholesteryl ester transfer revealed a redistribution of CETP resembling that resulting from in vitro lipolysis and an increase in total CETP activity. While this manuscript was in preparation, Castro and Fielding (21) reported a marked stimulation of cholesteryl ester transfer in alimentary lipemic plasma.

\section{Methods}

Human subjects. The study subjects were seven normolipidemic nonsmoking healthy volunteers, aged 22-38-yr-old, recruited from Medical Center personnel. The range of fasting triglycerides was $35-107 \mathrm{mg} / \mathrm{dl}$

1. Abbreviations used in this paper: apos A-I and B, apolipoproteins AI and B, respectively; CETP, cholesteryl ester transfer protein; LCAT, lecithin:cholesterol acyltransferase. 
and of cholesterol was $140-235 \mathrm{mg} / \mathrm{dl}$. After a 14-h overnight fast, a blood sample was collected in sodium EDTA-containing tubes, cooled in ice, and the plasma was obtained immediately by centrifugation. The subjects ingested 1 pint of heavy cream $(\sim 135 \mathrm{~g}$ triglyceride), then $6 \mathrm{~h}$ later another plasma sample was obtained. At this time the postprandial changes in HDL are most pronounced (20). The study was approved by the Institutional Review Board of Columbia University.

Materials. Plasma LDL and HDL were isolated from fasting and lipemic plasma by preparative ultracentrifugation between 1.02 to 1.063 and 1.063 to $1.210 \mathrm{~g} / \mathrm{ml}$, respectively. Phospholipid-enriched HDL were prepared as described previously (22). Sonicated unilamellar vesicles of egg phosphatidylcholine $(8 \mathrm{mg}$ ) were incubated in $5 \mathrm{ml}$ fresh, pooled Blood Bank plasma for $2 \mathrm{~h}$ at $37^{\circ} \mathrm{C}$ in the presence of $2 \mathrm{mM}$ dithionitrobenzoic acid (an inhibitor of LCAT), followed by isolation of phospholipid-enriched HDL between 1.10 and $1.21 \mathrm{~g} / \mathrm{ml}$. To obtain fatty acid-enriched HDL, oleic acid $(1.6 \mathrm{mg})$ was dried down from benzene, brought up in $100 \mu$ l ethanol, $80 \mu \mathrm{l}$ of $1 \mathrm{M} \mathrm{NaOH}$ was added, and the mixture was vortexed and dried under $\mathrm{N}_{2} .500 \mu \mathrm{l}$ of hot $\left(70^{\circ} \mathrm{C}\right)$ water was added; the solution was vortexed and then added slowly to $7 \mathrm{ml}$ plasma $\left(37^{\circ} \mathrm{C}\right)$. The HDL was subsequently isolated by preparative ultracentrifugation between 1.10 and $1.21 \mathrm{~g} / \mathrm{ml}$. Lipid compositional analysis of $\mathrm{HDL}$ was performed as described previously (14). $\mathrm{HDL}_{3}$ containing radiolabeled cholesteryl esters was prepared by injecting $200 \mu \mathrm{Ci}$ of ${ }^{3} \mathrm{H}$ cholesterol (in $50 \mu \mathrm{l}$ ethanol) through a 25 -gauge needle beneath the surface of $110 \mathrm{ml}$ stirred, dialyzed fresh plasma $d>1.10-\mathrm{g} / \mathrm{ml}$ fraction, followed by incubation for $6 \mathrm{~h}$ at $37^{\circ} \mathrm{C}$, centrifugation at $1.21 \mathrm{~g} / \mathrm{ml}$, incubation with a 20-fold excess of LDL to remove $\left[{ }^{3} \mathrm{H}\right]$ cholesterol, then recentrifugation at $1.10 \mathrm{~g} / \mathrm{ml}$. The HDL contained $96 \%$ of radioactivity in cholesteryl esters and $4 \%$ in cholesterol. The specific activity was $\sim 20,000 \mathrm{dpm} / \mu \mathrm{g}$ cholesterol. CETP was purified from pooled Blood Bank plasma through the carboxymethylcellulose step (10). Based on activity, the preparation was purified 2,000 -fold relative to the $d>1.21$ $\mathrm{g} / \mathrm{ml}$ fraction of plasma.

Measurements of LCAT and cholesteryl ester transfer. LCAT activity was measured from the decrease in mass of cholesterol in plasma incubated for $0,1,2$, or $6 \mathrm{~h}$ at $37^{\circ} \mathrm{C}$. Cholesteryl ester mass transfer was assessed as described previously (23). At each time point an aliquot of the incubated plasma was chilled on ice and the mass of cholesterol and cholesteryl ester was determined in HDL and in the apolipoprotein (apo B)-containing lipoproteins. Cholesterol and total cholesterol (free plus esterified) were measured in whole plasma, using an enzymatic method (24), and cholesteryl ester mass was calculated by difference. Cholesterol and total cholesterol were measured in the HDL-containing supernatant after precipitation of apo B-containing lipoproteins with 0.1 vol of heparin/ $\mathrm{MnCl}_{2}(25)$. The mass of cholesteryl esters in the apo B-containing lipoproteins was calculated by subtracting the cholesteryl ester mass in the supernatant from that of total plasma. The time course of cholesteryl ester transfer was determined from the rate of increase in mass of cholesteryl esters in the apo B-containing lipoproteins, or, in experiments where LCAT was inhibited by $2 \mathrm{mM}$ dithionitrobenzoic acid, from the decrease in mass of cholesteryl esters in the HDL. For each subject the cholesteryl ester transfer assay was performed in pentuplicate and each sample was analyzed in duplicate. The assay was repeated three or four times for each subject. For the cholesteryl ester transfer assay, the within assay coefficient of variation was $\sim 10 \%(n=5)$, and the between assay coefficient of variation in the same subject was $\sim 23 \%(n=4)$. In selected experiments, cholesteryl ester mass transfer was also determined from the increase in mass of cholesteryl ester in the $d<1.063-\mathrm{g} / \mathrm{ml}$ fraction after incubation of plasma.

To prepare lipoprotein fractions for reconstitution experiments, fasting or lipemic plasma was centrifuged at $d 1.063 \mathrm{~g} / \mathrm{ml}$ in sealed polyallomer tubes for $16 \mathrm{~h}$ at $40,000 \mathrm{rpm}$ in a Ti 50.3 rotor. Equal volumes of top and bottom fractions were obtained from the tubes and dialyzed against $50 \mathrm{mM}$ Tris-saline, $\mathrm{pH}$ 7.4. In some experiments, HDL containing radiolabeled cholesteryl esters was added to the $d>1.063-\mathrm{g} / \mathrm{ml}$ fraction in order to compare the transfer of cholesteryl ester mass and radioactivity during the subsequent recombination experiments. In one experiment the $d>1.063$ fraction was equilibrated with HDL containing radiolabeled cholesteryl esters by preincubation of the tracer with the $d>1.063$ fraction for $4 \mathrm{~h}$ at $37^{\circ} \mathrm{C}$ before addition of the $d<1.063$ fraction. The results of this experiment (not shown) were almost identical to those in which the tracer was not preequilibrated with the HDL.

Distribution of CETP in plasma. The distribution of CETP was assessed by measuring its activity in fractions of plasma $(14,26) .3 \mathrm{ml}$ of fresh plasma was subjected to chromatography on a $170 \times 1.5-\mathrm{cm}$ column of 10\% agarose (200-400 mesh) (Bio-Rad Laboratories, Richmond, CA). The profile of cholesterol in the column fractions was determined and then to a $1.6-\mathrm{ml}$ aliquot of each fraction was added LDL ( $0.2 \mathrm{mg}$ protein) and HDL containing radiolabeled cholesteryl esters ( $1 \mu \mathrm{g}$ cholesterol, $10,000 \mathrm{cpm}$ ). Unlabeled pooled HDL was also added to give a total mass of $50 \mu \mathrm{g}$ HDL cholesterol so that the specific activity of the donor HDL would be the same $(10,000 \mathrm{cpm} / 50 \mu \mathrm{g}$ cholesterol $)$ in each fraction. The

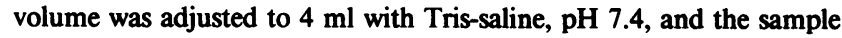
was incubated for $2 \mathrm{~h}$ at $37^{\circ} \mathrm{C}$ then centrifuged at $d 1.063 \mathrm{~g} / \mathrm{ml}$ for 16 $h$ at 40,000 rpm in a Sorvall 45 rotor (Dupont Instruments, Wilmington, DE). The radioactivity present in the top $2 \mathrm{ml}$ was determined. The amount of cholesteryl ester radioactivity transferred into this fraction (minus a blank value, generally $<10 \%$ of the total radioactivity transferred, obtained by incubating LDL and radiolabeled HDL in the absence of the fraction) is referred to as the cholesteryl ester transfer activity or as CETP activity units. In some experiments, radiolabeled LDL (prepared by incubating LDL with HDL containing radiolabeled cholesteryl esters in the presence of CETP, followed by ultracentrifugal separation of the LDL at $1.063 \mathrm{~g} / \mathrm{ml}$ ) was used as the donor of cholesteryl ester radioactivity and HDL as the acceptor.

Apo A-I affinity chromatography. Antibodies against pure human apo A-I were raised in the rabbit. Specific apo A-I antibodies were purified by HDL affinity chromatography (27). Antibodies eluted from the HDL column between $\mathrm{pH} 3$ and 4 were used to construct the apo A-I affinity column by cross-linkage to $\mathrm{CNBr}$-activated Sepharose $4 \mathrm{~B}(28)$. This column was shown to remove all of the apo A-I present in the 1-ml plasma samples by $(a)$ sodium dodecyl sulfate gel analysis of the void and retained fractions and $(b)$ rechromatography of the void fraction (which did not yield a second retained fraction). $1 \mathrm{ml}$ plasma was mixed with $1 \mathrm{ml}$ of Tris-saline, $\mathrm{pH} 7.4$, applied to the column, incubated at room temperature for $20 \mathrm{~min}$, then washed with several bed volumes of Tris-saline, $\mathrm{pH}$ 7.4, until the $A_{280}$ had reached baseline. The retained fraction containing HDL and its bound CETP was eluted with $0.1 \mathrm{M}$ acetic acid, $\mathrm{pH}$ 3.0. The activity of CETP in the void and retained fractions was determined after adjustment of the pH to 7.4 and addition of LDL and HDL containing radiolabeled cholesteryl esters. Exposure of purified CETP to the $\mathrm{pH} 3.0$ buffer for $1 \mathrm{~h}$ at room temperature did not result in loss of activity. All results are given as mean \pm SEM unless otherwise indicated.

\section{Results}

Cholesteryl ester transfer in native and reconstituted fasting and lipemic plasma. Incubation of plasma obtained from seven subjects during alimentary lipemia showed a 2-3-fold stimulation of cholesteryl ester transfer from HDL to apo B-containing lipoproteins (Fig. 1). Cholesteryl ester transfer proceeded in an approximately linear fashion during the 6-h incubation. Alimentary lipemia was also associated with a slight increase in activity of LCAT, as reported previously $(21,29)$. At 1,2 , and $6 \mathrm{~h}$ the mean \pm SEM values for LCAT activity were $15 \pm 1,24 \pm 1$, and $91 \pm 3$ (fasting), and $21 \pm 2,33 \pm 2$, and $97 \pm 1$ (lipemic) $\mu \mathrm{g}$ cholesterol esterified per $\mathrm{ml}$ plasma $(n=7$; differences significant, $P<0.05$, at 1 and $2 \mathrm{~h}$ ). In fasting or lipemic plasma from three subjects, the measured cholesteryl ester transfer was identical with or without the LCAT inhibitor, $2 \mathrm{mM}$ dithionitrobenzoic acid (not shown), indicating that the stimulation of cholesteryl ester transfer was not secondary to enhancement of LCAT activity.

In Fig. 1, cholesteryl ester transfer was calculated by sub- 


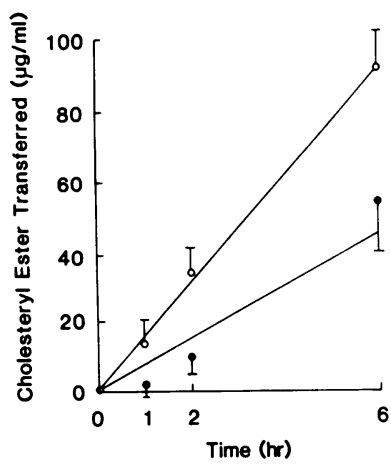

Figure 1. Transfer of cholesteryl esters from HDL to apo B-containing lipoproteins in fasting $(\bullet)$ or lipemic (O) plasma incubated for the indicated times. HDL and apo Bcontaining lipoproteins were separated by heparin/ $\mathrm{MnCl}_{2}$ precipitation (23). Cholesteryl ester transfer was calculated as described in Methods. The differences were significant at $2 \mathrm{~h}(P<0.02)$ and $6 \mathrm{~h}$ $(P<0.05)(n=7)$.

tracting $\mathrm{HDL}$ cholesteryl ester mass (heparin/ $\mathrm{MnCl}_{2}$ supernatant) from total plasma cholesteryl ester mass. To measure the transfer of cholesteryl esters more directly, plasma was incubated at $37^{\circ} \mathrm{C}$, then subjected to ultracentrifugation at $1.063 \mathrm{~g} / \mathrm{ml}$. Compared with fasting plasma, the incubation of lipemic plasma resulted in a threefold greater increase in mass of cholesteryl esters in the $d<1.063-\mathrm{g} / \mathrm{ml}$ fraction. Since there is very little LCAT activity in $d<1.063$ lipoproteins, ${ }^{2}$ these results also demonstrate the stimulation of transfer of cholesteryl esters into $d$ $<1.063-\mathrm{g} / \mathrm{ml}$ lipoproteins during alimentary lipemia.

Further experiments were directed towards an investigation of the mechanism of stimulated cholesteryl ester transfer in alimentary lipemic plasma. To determine which fraction of lipemic plasma was responsible for the stimulation of cholesteryl ester transfer, fasting and lipemic plasma were subject to ultracentrifugation at $1.063 \mathrm{~g} / \mathrm{ml}$. The $d<1.063-$ and $d>1.063-\mathrm{g} / \mathrm{ml}$ fractions were then recombined with each other or with the complementary fraction of the other plasma sample. Table I shows that reconstituted lipemic plasma showed greater stimulation of LCAT and cholesteryl ester transfer than reconstituted fasting plasma. The cholesteryl ester transfer activity of the reconstituted fasting plasma was very low, reflecting the low levels of plasma triglyceride $(35-50 \mathrm{mg} / \mathrm{dl})$ in the plasma samples used for these experiments. When recombined with the complementary fractions of fasting plasma, both the $d<1.063$ and $d>1.063$ fractions of lipemic plasma gave rise to significant stimulation of LCAT activity and cholesteryl ester transfer, compared with reconstituted fasting plasma.

Subsequent experiments aimed at investigating the mechanisms of cholesteryl ester transfer employed radiolabeled cholesteryl esters. To determine if the pattern of transfer of radiolabeled HDL cholesteryl esters was similar to that of cholesteryl ester mass, we measured the transfer of radiolabeled cholesteryl esters from HDL to $d<1.063-\mathrm{g} / \mathrm{ml}$ lipoproteins in reconstituted fasting and lipemic plasma. These experiments showed stimulation of the transfer of radiolabeled cholesteryl esters in reconstituted lipemic plasma compared with reconstituted fasting plasma (Table II). As in the mass experiments, the stimulatory properties of lipemic plasma resided in both the $d<1.063$ and $d>1.063$ fractions.

Although the pattern of stimulation of the transfer of radiolabeled cholesteryl esters was similar to that of cholesteryl ester mass, the lipemic fractions produced a more pronounced increase in mass transfer (see Tables I and II). This could arise if

2. Using the technique outlined in reference 36 , we found $<5 \%$ of total plasma LCAT activity associated with the $d<1.063$ lipoproteins in both fasting and lipemic plasma.
Table I. Effect of Recombination of Fractions of Fasting and Lipemic Plasma on Cholesteryl Ester Transfer*

\begin{tabular}{llc}
\hline Mixture & LCAT & $\begin{array}{l}\text { Cholesteryl } \\
\text { ester transfer }\end{array}$ \\
\hline & $\mu g / m l$ & $\mu g / m l$ \\
A. $d<1.063(\mathrm{f})+d>1.063(\mathrm{f})$ & $44 \pm 7$ & $5 \pm 8$ \\
B. $d<1.063(\mathrm{f})+d>1.063(\mathrm{l})$ & $72 \pm 12$ & $38 \pm 6$ \\
C. $d<1.063(\mathrm{l})+d>1.063(\mathrm{l})$ & $60 \pm 6$ & $48 \pm 9$ \\
D. $d<1.063(\mathrm{l})+d>1.063(\mathrm{f})$ & $50 \pm 9$ & $45 \pm 4$
\end{tabular}

* $5 \mathrm{ml}$ of fasting or lipemic plasma was subject to ultracentrifugation at $1.063 \mathrm{~g} / \mathrm{ml}$ for $16 \mathrm{~h}$ in a 50.3 rotor at $40,000 \mathrm{rpm}$. The top and bottom $2 \mathrm{ml}$ were removed, dialyzed for $2 \mathrm{~h}$ against Tris-saline, $\mathrm{pH}$ 7.4 , then reconstituted as shown above (f and 1 denote samples from fasting or lipemic plasma, respectively) and incubated for $6 \mathrm{~h}$ at $37^{\circ} \mathrm{C}$. Subsequently, the samples were subject to ultracentrifugation at 1.063 $\mathrm{g} / \mathrm{ml}$. The activity of LCAT was determined from the decrease in mass of unesterified cholesterol in the $d<1.063$ fraction and cholesteryl ester transfer from the increase in mass of cholesteryl ester in this fraction. The results are expressed as microgram per milliliter plasma ( $n=6$ experiments, three donors). Recombinations B, C, and D all showed significantly $(P<0.05)$ greater LCAT activity and cholesteryl ester transfer than recombination $\mathrm{A}$.

in reconstituted fasting plasma most of the transfer of radiolabeled cholesteryl ester results from an exchange process, whereas in reconstituted lipemic plasma there is both an increase in the total amount of exchange and also an increased proportion of the total exchange devoted to net transfer because of the enrichment of the lipemic $d<1.063$ fraction with triglycerides (12). To test this hypothesis, the $d>1.063$ fractions of lipemic and fasting plasma were reconstituted with increasing amounts of triglyceride-rich VLDL, in the presence of a constant amount of cholesteryl ester-rich LDL. The LDL and VLDL had been isolated from pooled plasma. In the absence of added VLDL, there was no significant net transfer of cholesteryl esters from HDL to apo B-containing lipoproteins, even though there was exchange of a major fraction of radiolabeled HDL cholesteryl esters with those of $d<1.063$ lipoproteins (Fig. 2). With the addition of increasing amounts of VLDL, there was a progressive stimulation of the mass transfer of HDL cholesteryl esters. The

Table II. Transfer of Radiolabeled Cholesteryl Esters from HDL to d $<1.063 \mathrm{~g} / \mathrm{ml}$ Lipoproteins in Reconstituted Fasting and Lipemic Plasma*

\begin{tabular}{ll} 
& \\
& $\begin{array}{l}\text { Transfer of } \\
\text { cholesteryl ester }\end{array}$ \\
\hline & cpm/incubation \\
A. $d<1.063(\mathrm{f})+d>1.063(\mathrm{f})$ & $172 \pm 9.5$ \\
B. $d<1.063(\mathrm{f})+d>1.063(\mathrm{l})$ & $336 \pm 4.3$ \\
C. $d<1.063(\mathrm{l})+d>1.063(\mathrm{l})$ & $461 \pm 7.7$ \\
D. $d<1.063(\mathrm{l})+d>1.063(\mathrm{f})$ & $222 \pm 17$
\end{tabular}

* The experiments were performed as described in Table I, except that HDL ( $1 \mu \mathrm{g}$ cholesterol) containing cholesteryl ester radioactivity $(10,000 \mathrm{cpm})$ was added to the $d>1.063$ fractions before recombination. The amount of cholesteryl ester radioactivity transferred into the $d<1.063$ fraction during a subsequent 2 -h recombination incubation was determined. 


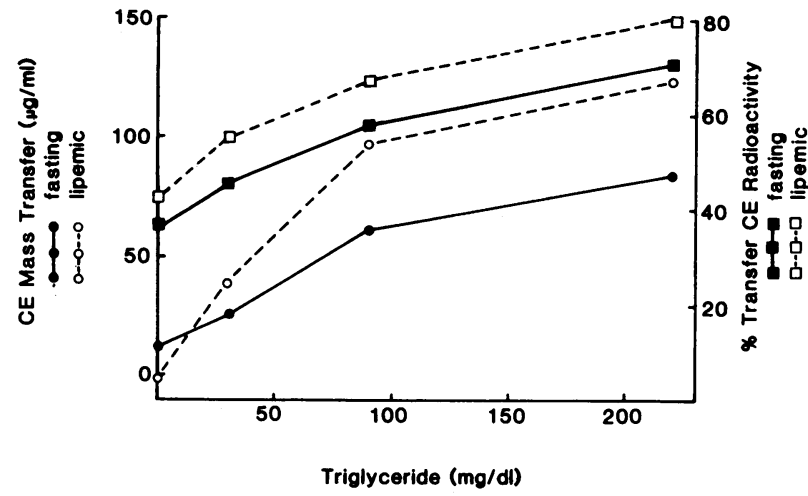

Figure 2. Transfer of cholesteryl ester (CE) mass or radioactivity from fasting or lipemic $d>1.063$ fractions to apo B-containing lipoproteins, as a function of increasing VLDL-triglyceride concentration. 5 $\mathrm{ml}$ of fasting or alimentary lipemic plasma was centrifuged at $d 1.063$ $\mathrm{g} / \mathrm{ml}$ for $20 \mathrm{~h}$ at $40,000 \mathrm{rpm}$ in a 50.3 rotor. The bottom $1.5 \mathrm{ml}(d$ $>1.063$ fraction) was dialyzed against Tris-saline, $\mathrm{pH} 7.4$, made 2 $\mathrm{mM}$ with DTNB, then incubated for $4 \mathrm{~h}$ at $37^{\circ} \mathrm{C}$ with radiolabeled HDL (180,000 cpm). Subsequently, LDL (1 mg cholesterol) and VLDL (in the amount shown on the $x$-axis) were added, the samples were adjusted to a final volume of $5 \mathrm{ml}$ and incubated for 0 or $6 \mathrm{~h}$ at $37^{\circ} \mathrm{C}$. After incubation, the samples were chilled on ice and apo Bcontaining lipoproteins were precipitated with heparin/ $/ \mathrm{MnCl}_{2}$. The radioactivity and mass of cholesteryl ester in the HDL-containing supernatant was determined and the transfer of cholesteryl ester radioactivity or mass was calculated by subtracting the 6-h from the 0 -h value. The results shown are the percentage of HDL cholesteryl ester radioactivity and the mass of HDL cholesteryl ester (microgram per milliliter of incubation mixture or plasma) undergoing transfer. The results shown are the mean values from three separate experiments using plasma from a single donor.

mass transfer was more pronounced in the presence of the lipemic $d>1.063$ fraction. The exchange of radiolabeled HDL cholesteryl esters was also more pronounced in the incubations containing the lipemic $d>1.063$ fraction. In shorter incubations where initial rates of exchange were measured (as in Table II), the stimulation of radiolabel transfer by the lipemic $d>1.063$ fraction was more pronounced ( 1.4-1.5-fold) (not shown). These results indicate that the stimulation of mass transfer during alimentary lipemia arises from both an increased concentration of triglyceride-rich lipoproteins and also from an increase in the total exchange of HDL cholesteryl esters with lipoproteins of the $d<1.063$ fraction. The mechanism of the latter effect was investigated further.

Distribution of CETP in plasma. In earlier studies, in vitro lipolysis stimulated cholesteryl ester exchange and transfer by increasing the binding of CETP to the lipoproteins $(13,14)$. To determine if alimentary lipemia gave rise to similar alterations in the pattern of binding of CETP to the lipoproteins, plasma of seven subjects was fractionated by agarose chromatography. The distribution of CETP was assessed by measuring its activity in individual column fractions (see Methods). In Fig. 3 are shown the results obtained in two of the male subjects, and in Fig. 4 are shown the results from two female subjects. The distributions of cholesterol and phospholipid across the column profiles are also shown in Fig. 4. In fasting plasma, most of the CETP activity was in HDL as reported (26). Under conditions of optimal resolution, we found that most of the CETP eluted with smaller HDL particles, and that there was also a variable fraction of CETP eluting in the region corresponding to nonlipoprotein-

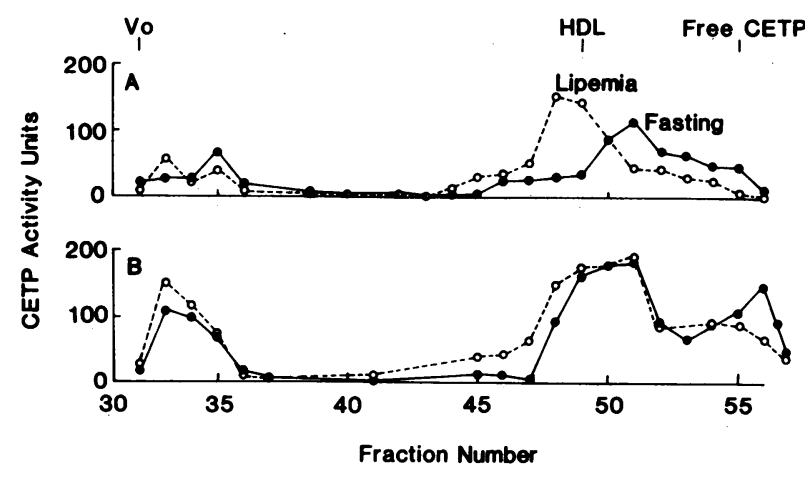

Figure 3. Distribution of CETP in fasting and lipemic plasma in two different male subjects (panels $A$ and $B$ ). $3 \mathrm{ml}$ of plasma was subjected to chromatography on a $170-\mathrm{cm} 10 \%$ agarose column. CETP activity was measured in each column fraction as described in Methods. Vo is the column void volume (where VLDL and LDL eluted). The elution volumes of a control preparation of HDL and of purified CETP are also shown.

bound CETP (Figs. 3 and 4). Two of the seven subjects (those with the highest fasting plasma triglycerides) also showed a definite peak of CETP activity in the void (VLDL plus LDL) fractions (Fig. $3 B$ and $4 F$ ). During lipemia, all subjects showed a redistribution of CETP from smaller to larger HDL and an increase in the ratio of HDL-bound CETP/free CETP. As assessed from the CETP activity eluting in the regions of $\mathrm{HDL}$ or free CETP, the ratio of HDL-bound/free CETP was 2.75 \pm .49 in fasting plasma and $4.0 \pm 0.6$ in lipemic plasma (difference significant, $P<0.01$ by paired $t$ test). The redistribution of CETP into larger HDL seemed more pronounced in subjects who showed a greater enrichment of HDL with phospholipids during lipemia (see Fig. $4 B$ and $E$ ). In two subjects there was also a definite increase in CETP in the void eluting fractions during alimentary lipemia. When the plasma of one of these subjects (shown in Fig. 4) was subjected to gel filtration on 6\% agarose in order to separate VLDL and LDL, the VLDL and LDL regions were found to contain approximately equal CETP activity during alimentary lipemia (not shown). The same distribution and amounts of CETP activity were observed when CETP activity was measured in an assay using LDL containing radiolabeled cholesteryl esters as donor and HDL as the acceptor particle or when heparin/ $\mathrm{MnCl}_{2}$ precipitation was used to separate the lipoproteins.

In addition to the redistribution of CETP activity during lipemia, there was also an increase in the total CETP activity measured across the lipoprotein profile (Figs. 3 and 4). In the seven different subjects, the sum of the CETP activities in individual column fractions was 1.1-1.7-fold greater in lipemic plasma than in fasting plasma $(P<0.05$ by paired $t$ test, mean \pm SEM increase $=1.3 \pm 0.09$ ). Further experiments confirmed the increase in total CETP activity in lipemic plasma and showed that it was independent of the endogenous plasma lipoproteins (see below).

Since the separation of lipoprotein-bound and free CETP by agarose chromatography was sometimes incomplete, we also determined the distribution of CETP by apo A-I affinity chromatography (Table III). Plasma from a subject lacking CETP activity in apo B-containing lipoproteins was passed over an apo A-I affinity column and the CETP activity in the void and retained fractions was determined. These experiments exploited 


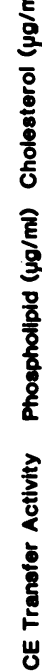

\section{A}
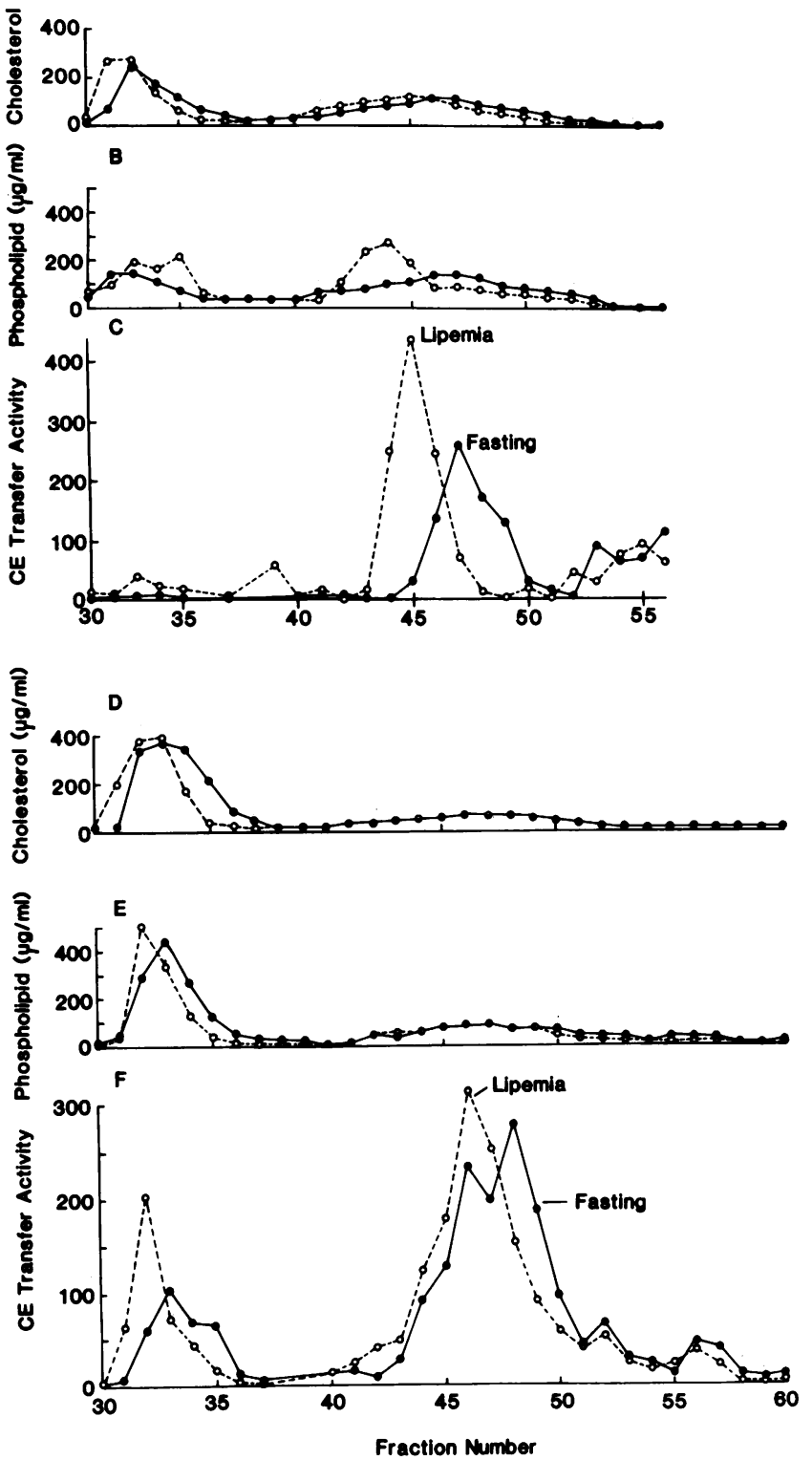

Figure 4. $(A-C)$ Distribution of CETP, cholesterol, and phospholipid in fasting (•) and lipemic (O) plasma from a female subject. $3 \mathrm{ml}$ plasma was analyzed as described in Methods. The concentrations of cholesterol and phospholipid are given in microgram per milliliter column fraction. Cholesteryl ester (CE) transfer activity is the cpm of cholesteryl ester radioactivity transferred per milliliter of column fraction in the standardized assay (see Methods). $(D-F)$ Distribution of cholesterol, phospholipid, and CETP in fasting and lipemic plasma of a different female subject.

the use of purified apo A-I antibodies which allow specific elution of HDL under relatively mild conditions, which did not adversely affect CETP activity (see Methods). The void eluting CETP activity represents nonlipoprotein-bound CETP, while that eluted at pH 3 represents HDL-bound CETP. In lipemic plasma there was a slight decrease in the void-recovered (free) CETP, an increase in the retained (HDL-bound) CETP, and an increase in the bound/free ratio. Although these results are not strictly quantitative (because the specific activity of donor lipoprotein
Table III. Distribution of CETP in Plasma as Determined by Apo A-I Affinity Chromatography*

\begin{tabular}{lcc}
\hline & \multicolumn{2}{l}{ CETP activity units } \\
\cline { 2 - 3 } & Fasting & Lipemic \\
\hline Void & $168 \pm 28$ & $142 \pm 27$ \\
Retained & $170 \pm 26$ & $247 \pm 16$ \\
Retained/void & $1.17 \pm 0.27$ & $2.18 \pm 0.6$
\end{tabular}

* $1 \mathrm{ml}$ of fasting or lipemic plasma was applied to the apo A-I column. The sample was allowed to equilibrate with the column for $1 \mathrm{~h}$ at $25^{\circ} \mathrm{C}$, then the column was washed with Tris-saline, $\mathrm{pH} 7.4$, until the $\mathrm{A} 280$ was zero. The retained fraction was eluted by applying 0.1 $\mathrm{M}$ acetic acid, $\mathrm{pH}$ 3.0. The $\mathrm{pH}$ of the retained fraction was adjusted to 7.4 by addition of $1 \mathrm{M}$ Tris buffer, then the cholesteryl ester transfer activity was determined by incubation of one-quarter of the void or retained fractions with $0.2 \mathrm{mg} \mathrm{LDL}$ and HDL ( $1 \mu \mathrm{g}$ cholesterol, 1,000 $\mathrm{cpm}$ ). The results are mean \pm SEM (five experiments). The retained/ void ratio was significantly greater for lipemic compared to fasting plasma $(P<0.05$ by paired $t$ test).

cholesteryl ester was different for the void and retained fractions), they corroborate the change in binding pattern shown by agarose chromatography.

Binding of CETP to HDL related to CETP activity. The distribution of CETP in plasma (Figs. 3 and 4, Table III) suggests that changes in HDL during alimentary lipemia lead to an increase in binding of CETP which, by analogy with the in vitro lipolysis experiments (14), results in stimulation of cholesteryl ester transfer. To examine this hypothesis directly we isolated HDL from fasting and lipemic plasma and then compared its ability to bind purified CETP. HDL was isolated by preparative ultracentrifugation between 1.063 and $1.210 \mathrm{~g} / \mathrm{ml}$, a procedure that results in dissociation of the endogenous CETP from HDL (26). The isolated HDL was then incubated with CETP purified from pooled blood bank plasma. The distributions of HDL cholesterol and purified CETP and the results for two of the binding studies are shown in Fig. 5. The lipemic HDL bound more CETP than the fasting HDL. In four such binding experiments conducted over a 10-fold range of CETP/HDL ratios (300 $\mu \mathrm{g}$ CETP/ $250 \mu \mathrm{g}$ HDL cholesterol to $30 \mu \mathrm{g} \mathrm{CETP/250} \mu \mathrm{g}$ HDL cholesterol), the HDL bound/free CETP ratio was $2.5 \pm 0.43$ for lipemic HDL and $1.6 \pm 0.28$ for fasting $\mathrm{HDL}(P<0.05$ by paired $t$ test). The bound $(\mathrm{B}) /$ free $(\mathrm{F})$ ratio $(\mathrm{B} / \mathrm{F})$ maintained an approximately constant relationship between the lipemic and fasting $\mathrm{HDL}$ at the four binding ratios, i.e., (B/F) lipemic/(B/F) fasting $=1.63 \pm 0.2$, consistent with an increase in the number binding sites for CETP on lipemic HDL.

Next we compared the isolated fasting and lipemic HDL as substrates for CETP in a cholesteryl ester exchange assay. HDL was incubated with purified CETP using similar ratios of CETP to HDL to those shown in Fig. 5, and the transfer of radiolabeled cholesteryl esters from fasting or lipemic HDL to pooled LDL was determined. The experiments showed that for the same amount of CETP and HDL cholesterol, the lipemic HDL supported 1.5-fold greater cholesteryl ester exchange than the fasting HDL (Fig. 6), consistent with the hypothesis that increased binding of CETP to lipemic HDL resulted in a greater stimulation of cholesteryl ester exchange. Similar results were obtained on four occasions using HDL isolated from two different subjects. 


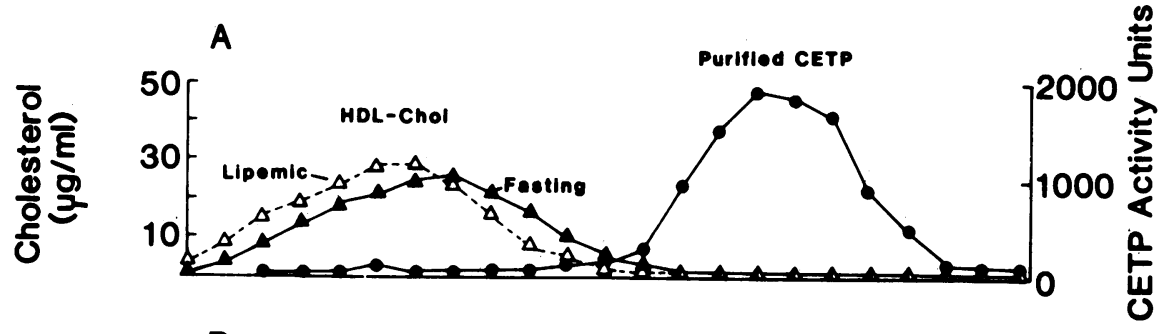

B

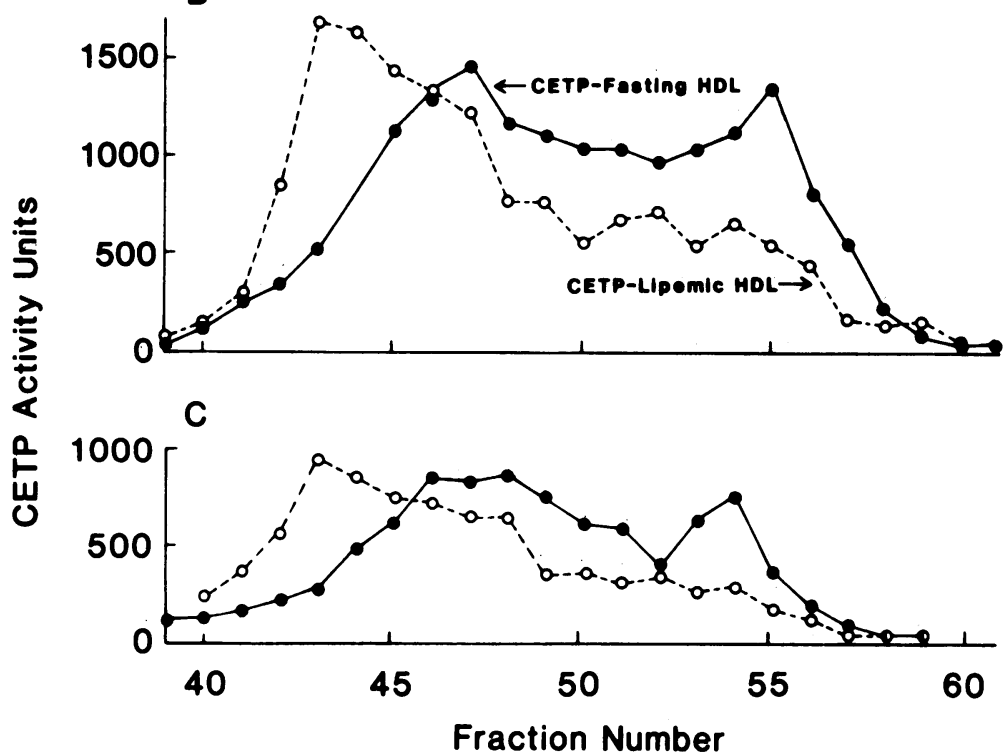

Figure 5. Binding of purified CETP to centrifugally isolated HDL from fasting or lipemic plasma. Purified CETP was incubated with $\mathrm{HDL}$ for $30 \mathrm{~min}$ at $37^{\circ} \mathrm{C}$ and then subjected to $10 \%$ agarose chromatography. $A$ shows the distribution of CETP incubated without HDL and also the distribution of cholesterol in HDL isolated from fasting and lipemic plasma. $B$ shows the distribution of CETP after incubation of $300 \mu \mathrm{g}$ CETP with $250 \mu \mathrm{g}$ HDL cholesterol. $C$ shows the distribution of CETP after incubation of $150 \mu \mathrm{g}$ CETP with $250 \mu \mathrm{g}$ HDL cholesterol. Recovery of CETP activity during chromatography was $\sim 85 \%$.
The results of the experiments shown in Fig. 4 and in our earlier studies (14) suggest that the increased binding of CETP by postlipolysis or lipemic HDL might be mediated by an increased content of phospholipids and/or fatty acids. Compositional analysis of HDL isolated from alimentary lipemic plasma showed a $10-40 \%$ increase in the ratio of phospholipid/total cholesterol as reported previously $(19,20)$. The binding of purified CETP by HDL enriched in vitro with phospholipids or with fatty acids is shown in Fig. 7. These experiments demonstrated a pronounced increase in the binding of CETP to both phospholipid- and fatty acid-enriched HDL particles, especially to the former. Compositional analysis showed that the phospholipid-enriched HDL contained an increase in the mass ratio of phospholipid/total cholesterol $(2.84 \mathrm{mg} / \mathrm{mg})$ compared with control HDL (1.51), and also in the mass ratio of fatty acid/

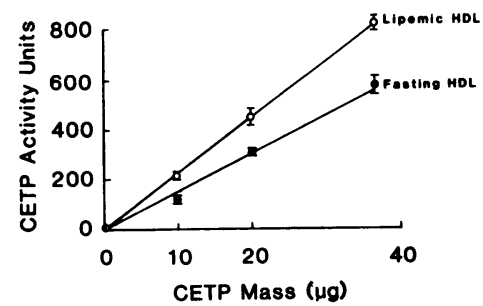

Figure 6. CETP-mediated transfer of cholesteryl ester radioactivity from isolated fasting or lipemic HDL to LDL. HDL was isolated by preparative ultracentrifugation from fasting or lipemic plasma. The HDL ( $25 \mu \mathrm{g}$ cholesterol) was preincu-

bated with HDL containing radiolabeled cholesteryl esters ( $1 \mu \mathrm{g}$ cholesterol, $10,000 \mathrm{cpm}$ ) for $4 \mathrm{~h}$ at $37^{\circ} \mathrm{C}$ to allow equilibration of the radiolabeled cholesteryl esters amongst the HDL. Subsequently, pooled human LDL ( $200 \mu \mathrm{g}$ cholesterol) was added and the samples were incubated for $2 \mathrm{~h}$ at $37^{\circ} \mathrm{C}$. The cholesteryl ester radioactivity (cpm) transferred into LDL during the second incubation are shown. The differences in mean values were significant at all time points $(P<0.01)$. total cholesterol $(0.25 \mathrm{mg} / \mathrm{mg})$, compared with control HDL (0.072), while the fatty acid-enriched HDL showed an increased ratio of fatty acid/cholesterol $(0.14)$, but only a slight change in phospholipid/cholesterol ratio (1.8). When incubated with purified CETP and LDL using the same protocol as described for fasting and lipemic HDL in Fig. 6, phospholipid-enriched HDL showed fourfold stimulation of the CETP-mediated transfer of radiolabeled cholesteryl esters from $\mathrm{HDL}$ to $\mathrm{LDL}$, compared with the control HDL isolated from incubated control plasma (Fig. 8). In a similar experiment, fatty acid-enriched HDL showed a 2.2-fold increase in cholesteryl ester exchange with LDL compared with control (not shown).

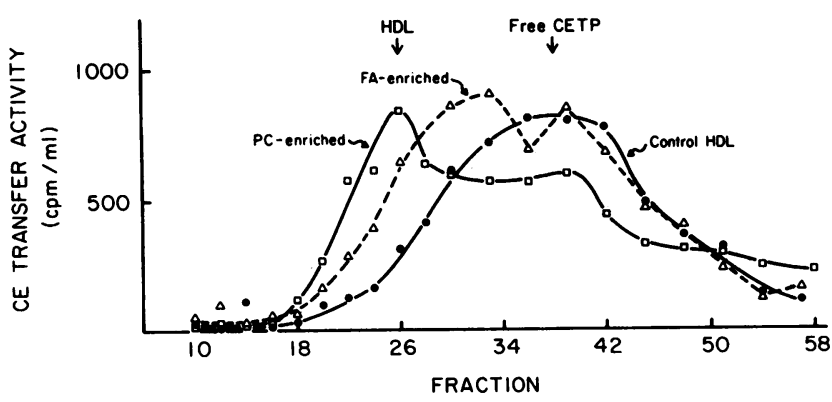

Figure 7. Distribution of CETP after incubation with control HDL or HDL that had been enriched with fatty acids or phospholipids by addition of fatty acids or phospholipids to plasma. HDL ( $100 \mu \mathrm{g}$ cholesterol) was incubated with $300 \mu \mathrm{g}$ CETP for $30 \mathrm{~min}$ at $37^{\circ} \mathrm{C}$ then subjected to chromatography on a $100-\mathrm{cm}$ column of $10 \%$ agarose. The activity of CETP in individual column fractions was determined as described in Methods. The elution volumes of control preparations of HDL or CETP are given. PC, phosphatidylcholine. 


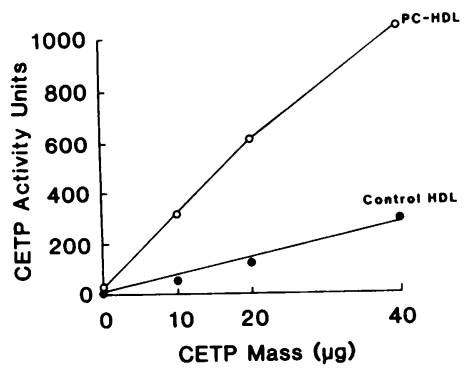

phatidylcholine vesicles. The results shown are the mean results from quadruplicate incubations conducted in two experiments.

In a further experiment designed to assess the effects of variation of plasma free fatty acid levels on CETP distribution, one subject was studied $6 \mathrm{~h}$ after ingestion of fat or $100 \mathrm{~g}$ carbohydrate. The plasma free fatty acid levels, determined as described (14,30), were $98 \mu \mathrm{g} / \mathrm{ml}$ (fasting), $145 \mu \mathrm{g} / \mathrm{ml}$ (lipemic), and 17 $\mu \mathrm{g} / \mathrm{ml}$ (after carbohydrate). In lipemic plasma there was a change in distribution and total amount of CETP activity in plasma as found earlier (Figs. 3 and 4). By contrast, after carbohydrate, there was no significant change in the distribution or amount of CETP compared with fasting plasma.

Increase in total activity of CETP during lipemia. The measurements of CETP activity (Figs. 3 and 4, Table I) indicate an increase in total activity in lipemic plasma compared with fasting plasma. To determine if this reflected an interaction of CETP with the endogenous plasma lipoproteins, CETP was dissociated from the endogenous lipoproteins and then its activity was assayed with exogenous pooled lipoproteins. To dissociate CETP from the endogenous lipoproteins, plasma was incubated and chromatographed at $\mathrm{pH} 5.5$, then the fractions were readjusted to pH 7.4 and assayed (14). These experiments showed a complete dissociation of CETP from the HDL, with elution of CETP activity in the same region as nonlipoprotein-bound purified CETP (Fig. 9). The total activity of CETP was, however, in- creased 1.7-fold in lipemic compared with fasting plasma. This was identical to the value that had been obtained by chromatography of the same plasma at $\mathrm{pH} 7.4$ (i.e., with CETP still bound to the endogenous lipoproteins).

In further experiments CETP was dissociated from the endogenous lipoproteins by prolonged ultracentrifugation at 1.21 $\mathrm{g} / \mathrm{ml}$. The activity of CETP measured in the $d>1.21 \mathrm{~g} / \mathrm{ml}$ fraction showed an $\sim 1$.2-fold increase in the lipemic fraction compared to fasting (Fig. 10). The recoveries of CETP activity were lower and the differences between fasting and lipemic plasma were less pronounced by the centrifugal method (see Fig. 9), reflecting the $5 \mathrm{~d}$ of centrifugation found necessary to obtain complete dissociation of CETP from the lipemic sample. To determine if the greater CETP activity present in lipemic plasma might reflect the presence of inhibitors of CETP in fasting plasma, mixing experiments were performed. These experiments showed that a 50/50 mixture of $100 \mu \mathrm{l}$ lipemic and fasting 1.21 bottom gave a mean response $(n=5)$ exactly intermediate between the fasting and lipemic values shown in Fig. 10. Furthermore, when the activity associated with column-separated lipemic and fasting HDL was assayed in progressive dilutions over a 50-fold range, the lipemic fractions showed a consistent 1.7 -fold greater activity than fasting fractions independent of dilution (not shown). These results are inconsistent with the effects of an inhibitor. In a further experiment designed to assess the potential role of inhibitors or activators of CETP, plasma CETP was dissociated from the endogenous plasma lipoproteins by agarose chromatography at $\mathrm{pH}$ 5.5 , then fractions containing CETP activity were pooled and the effects of addition of exogenous purified CETP were determined. These results showed parallel increases in CETP activity over those of lipemic and fasting fractions, indicating that if there were activating or inhibitory factors they would not act on added purified CETP (Fig. 11).

To determine the time course of the increase in total activity of CETP, two subjects were administered fat and the activity of CETP, dissociated from the endogenous lipoproteins, was mea-

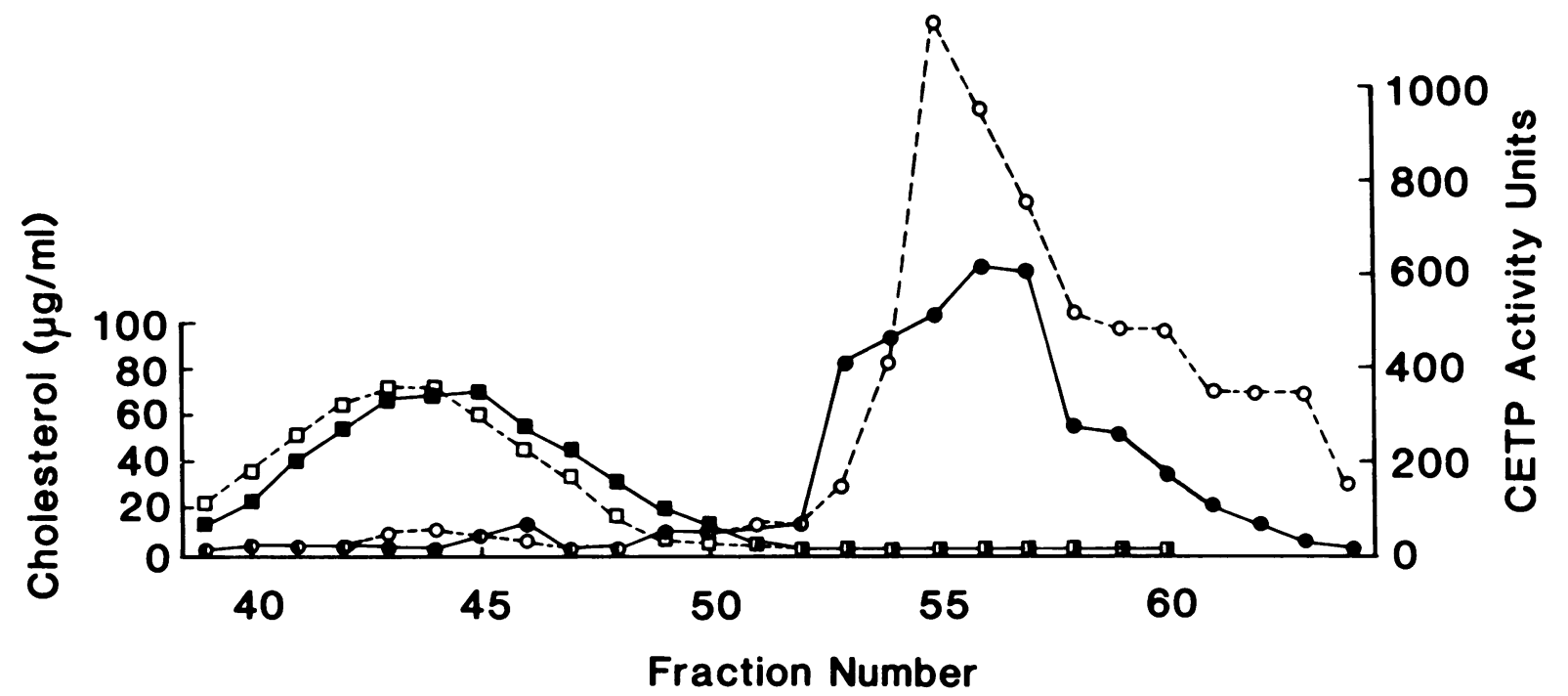

Figure 9. Distribution of HDL cholesterol (squares) and CETP (circles) in fasting (closed symbols) and lipemic (open symbols) plasma after release of CETP from the lipoproteins by lowering the $\mathrm{pH}$ to 5.5 . Plasma was adjusted to $\mathrm{pH} 5.5$ by addition of acetic acid, incubated for $1 \mathrm{~h}$ at $37^{\circ} \mathrm{C}$, then subjected to chromatography on a $170-\mathrm{cm}$ col- umn of $10 \%$ agarose preequilibrated with $100 \mathrm{mM}$ Tris-acetate, $\mathrm{pH}$ 5.5. The fractions were adjusted to $\mathrm{pH} 8.0$ by addition of $1 \mathrm{M}$ Tris, pH 9.0, then individually assayed for CETP activity and for cholesterol content. 


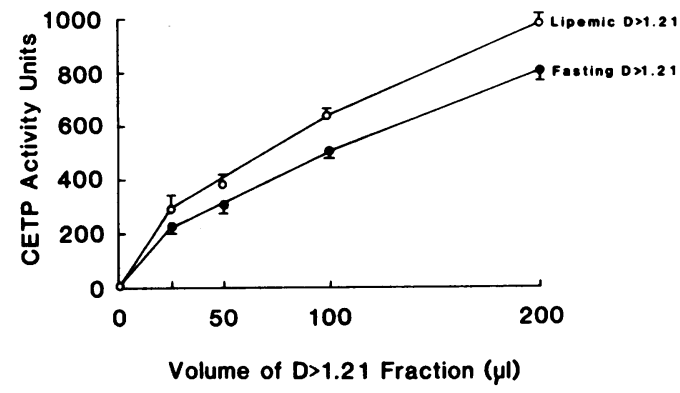

Figure 10. CETP activity present in the $d>1.21-\mathrm{g} / \mathrm{ml}$ fraction of fasting and lipemic plasma. $5 \mathrm{ml}$ of fasting or lipemic plasma was centrifuged at $1.21 \mathrm{~g} / \mathrm{ml}$ for $5 \mathrm{~d}$ at $\mathbf{4 0 , 0 0 0 ~ r p m ~ i n ~ a ~ B e c k m a n ~} 50.3$ rotor. The bottom $2 \mathrm{ml}$ of the tubes were taken and assayed for cholesteryl ester transfer activity using $0.2 \mathrm{mg} \mathrm{LDL}$ and HDL $(1 \mu \mathrm{g}$ cholesterol, $10,000 \mathrm{cpm}$ ). The radioactivity transferred into LDL during a 2-h incubation is shown. The differences of the means were statistically significant at 100 and $200 \mu \mathrm{l}(P<0.05, n=4)$.

sured after chromatography at pH 5.5 on short agarose columns. The maximum increase in CETP occurred 1 to $2 \mathrm{~h}$ after the peak in plasma triglycerides (Fig. 12).

\section{Discussion}

The present study shows an increase in the velocity of transfer of cholesteryl esters from HDL to apo B-containing lipoproteins in incubated plasma from subjects during alimentary lipemia, compared with fasting plasma. Similar findings were recently reported by Castro and Fielding (21) and in preliminary form in an earlier study by Rose and Juliano (29). Since cholesteryl ester transfer between lipoproteins is mediated by a plasma CETP, we sought to relate the phenomenon of enhanced cholesteryl ester transfer to the distribution and amounts of the CETP. These studies showed increased binding of CETP to the plasma lipoproteins, especially to HDL, analogous to that occurring as a result of in vitro lipolysis (14), and also an increase in the total activity of CETP in plasma during alimentary lipemia. Both of these factors, as well as the increase in mass of triglyceride-containing acceptor lipoproteins, contribute to the stimulation of cholesteryl ester transfer during alimentary lipemia.

Recombination experiments showed stimulation of cholesteryl ester transfer from HDL to the $d<1.063$ fraction when the lipemic $d<1.063$ fraction was reconstituted with the fasting $d>1.063$ fraction, suggesting that alterations in the amount or

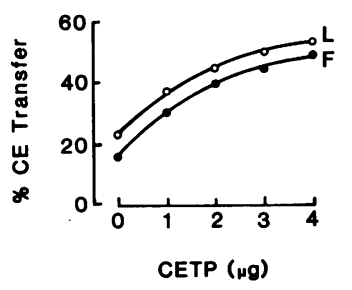

Figure 11. Cholesteryl ester (CE) transfer activity recovered after addition of purified CETP to fractions containing endogenous plasma CETP liberated from fasting $(\mathrm{F})$ or lipemic (L) plasma lipoproteins by chromatography at $\mathrm{pH}$ 5.5. Plasma was subjected to chromatography as described in the legend of Fig. 9, except that a 40-cm column was used. The fractions containing endogenous CETP liberated from the lipoproteins were identified (by assaying an aliquot for CE transfer activity), pooled, and then reassayed (with $100 \mu \mathrm{g} \mathrm{LDL}$ protein and HDL [5,000 cpm]) after addition of exogenous purified CETP in the amounts shown. The percentage radiolabeled HDL cholesteryl esters transferred into LDL is shown.

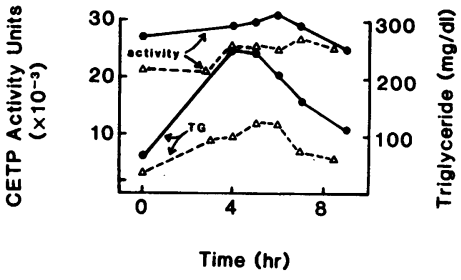

Figure 12. Plasma triglyceride levels and apparent mass of CETP (total CETP activity in lipoprotein-free plasma) after fat ingestion in two male subjects (shown by triangles or circles). The relative mass of CETP at

the different time points was inferred by assaying the cholesteryl ester transfer activity in lipoprotein-free plasma fractions obtained by chromatography of plasma, obtained at each time point, at pH 5.5, as described in Fig. 9, using $40-\mathrm{cm} 10 \%$ agarose columns. The total activity at each time point was obtained by summing the values of individual fractions. Each point is the mean value obtained from 2 to 4 column runs.

quality of acceptor lipoproteins (VLDL and LDL) were in part responsible for the stimulation of cholesteryl ester transfer during alimentary lipemia. The importance of increasing amounts of triglyceride-rich acceptor lipoproteins was demonstrated by reconstituting the $d>1.063$ fractions with a constant amount of LDL and increasing amounts of VLDL (Fig. 2). The results showed that increasing amounts of triglyceride-rich lipoproteins caused both an increase in total exchange of HDL cholesteryl esters and also an increase in the fraction of total exchange devoted to net transfer of HDL cholesteryl esters. The increase in total exchange reflects an increase in the concentration of acceptor lipoproteins and an increase in the ratio of acceptor lipoproteins to HDL $(31,32)$. The increased fraction of total exchange devoted to net transfer is presumably due to an increase in the ratio of triglyceride/cholesteryl esters in $d<1.063$ lipoproteins, resulting in increased heteroexchange of HDL cholesteryl esters with $d<1.063$ triglycerides $(12,33,34)$. Thus, during alimentary lipemia, a major factor resulting in increased net transfer of HDL cholesteryl is the increase in triglyceride-enriched acceptor lipoproteins.

The recombination experiments indicated that the stimulation of cholesteryl exchange and transfer during lipemia also reflected in part alterations in the lipemic $d>1.063$ fraction. The stimulatory property of the $d>1.063$ fraction was documented in three different types of experiments (Tables I and II, and Fig. 2). The magnitude of this effect appeared somewhat variable in the different experiments reflecting the different experimental conditions (e.g., different donor plasmas) and errors in the measurements of small changes in cholesterol mass. However, this was clearly a major effect responsible for a significant part of the overall increase in cholesteryl ester transfer during lipemia. The stimulation of cholesteryl ester transfer by the $d$ $>1.063$ fraction resulted from both an altered pattern of binding of CETP to HDL and also an increase in the total activity of CETP. We have recently shown that lipoprotein lipase activity results in enhanced CETP-mediated transfer of cholesteryl esters from HDL to VLDL (13), as a result of increased binding of CETP to both VLDL remnants and to HDL after lipolysis (14). An analogous increase in the binding of CETP to HDL and/or to fractions containing remnants of triglyceride-rich lipoproteins was in fact observed during alimentary lipemia. In most of the subjects, the most pronounced change in CETP distribution was a shift from smaller to larger $\mathrm{HDL}$ and an increase in the ratio of HDL-bound to free CETP, a pattern quite similar to that occurring as a result of in vitro lipolysis (14). The earlier studies suggest that increased binding of CETP to the lipoproteins is 
causally related to enhanced cholesteryl ester transfer (14). Furthermore, in the present study, HDL isolated from alimentary lipemic plasma was shown to bind increased amounts of purified CETP, compared with HDL isolated from fasting plasma, and to cause a parallel stimulation of CETP activity (Figs. 5 and 6).

The important compositional alteration of HDL causing increased binding of CETP appeared to be enrichment with phospholipids and/or fatty acids. Pattnaik and Zilversmit (26) established a primary role of the phosphorylcholine moiety of HDL phosphatidylcholine in mediating the binding of CETP, but also showed that an increase in lipoprotein negative charge, for example, as a result of an increase in negatively charged fatty acids, resulted in enhanced binding of CETP. In our in vitro lipolysis studies, we found that increased binding of CETP was related to accumulation of fatty acids in VLDL remnants and fatty acids and phospholipids in HDL (14). In the present investigation the major changes seemed to be in the HDL and were parallel to the enrichment of HDL with phospholipids; in vivo, the accumulation of fatty acids in the lipoproteins is much less pronounced than during in vitro lipolysis, possibly accounting for the quantitative differences in distribution of CETP in plasma compared with in vitro lipolysis mixtures $(13,14)$. In a single subject we found that marked reductions in plasma free fatty acid levels associated with carbohydrate ingestion were not associated with changes of the pattern of binding of CETP to HDL. However, the phospholipid-enriched HDL did contain considerably increased amounts of fatty acids, suggesting that the partition of fatty acids between the lipoproteins and albumin may be influenced by the phospholipid content of HDL. Also, the endogenous CETP of plasma was liberated from its lipoprotein binding sites by lowering the $\mathrm{pH}$ to 5.5 , a phenomenon that may be related to protonation of fatty acids present in the lipoprotein surface (14). It is possible that the CETP binding site involves a complex arrangement of lipoprotein surface lipids including both phospholipids and fatty acids, even though acute changes in plasma free fatty acid levels probably do not have a major influence on the amount or distribution of CETP.

A surprising result was that in addition to the redistribution of CETP during alimentary lipemia, there was also an increase in total CETP activity in plasma. The increase in total CETP activity was shown by summing the cholesteryl ester transfer activity of individual agarose column fractions. This finding was not related to changes in the endogenous plasma lipoproteins present in the assay mixture. The HDL isolated from the plasma of the subject shown in the bottom of Fig. 4 showed increased binding of purified CETP, but the total recovery of CETP activity after incubation with lipemic or fasting HDL was identical (Fig. 5). Also, phospholipid-enriched HDL bound more CETP than control HDL (Fig. 7), but the total recovery of CETP activity was the same for the two HDL preparations. Furthermore, an increase in total CETP activity was observed when lipoproteinfree plasma, prepared either by ultracentrifugation or agarose chromatography, was assayed for CETP activity, using pooled lipoproteins as substrates. These findings could be explained by an increase in plasma CETP mass during alimentary lipemia. However, confirmation of this hypothesis will require direct measurement of mass by immunoassay.

The three factors putatively identified as promoting mass transfer of HDL cholesteryl esters into $d<1.063$ lipoproteins show positive interaction. Thus, increased binding of CETP to HDL is synergistic with increased mass of CETP to produce an increase in the total exchange of HDL cholesteryl esters with those of other lipoproteins (Fig. 8). An increased fraction of this augmented total exchange becomes devoted to net transfer as a result of the increased ratio of triglyceride/cholesteryl esters in acceptor lipoproteins (Fig. 2). In different subjects the various factors promoting cholesteryl ester mass transfer exceed the small increase in LCAT activity, and therefore may produce a fall in HDL cholesterol mass. Prior studies of alimentary lipemia have shown that in different subjects the increase in HDL triglycerides and the decrease in HDL cholesteryl ester mass are, respectively, positively or negatively correlated with the degree of elevation of plasma triglyceride levels $(29,35)$; subjects with sluggish clearance of lipemia also have low fasting HDL cholesterol mass (36). As a result of the various mechanisms elucidated in this study, subjects with low HDL cholesterol levels might have accelerated transfer of cholesteryl esters into triglyceride-rich lipoproteins during lipemia, contributing to cholesteryl ester accumulation in atherogenic apo B-containing lipoproteins.

\section{Acknowledgments}

This work was supported by National Institutes of Health grants 22682 and T-07343. Dr. Tall is an Established Investigator of the American Heart Association.

\section{References}

1. Nichols, A. V., and L. Smith. 1965. Effect of very low-density lipoproteins on lipid transfer in incubated serum. J. Lipid Res. 6:205210.

2. Glomset, J. A., and K. R. Norum. 1973. The metabolic role of lecithin: cholesterol acyltransferase: perspectives from pathology. $A d v$. Lipid Res. 1:1-65.

3. Mahley, R. W., D. Y. Hui, T. L. Innerarity, and K. H. Weisgraber. 1981. Two independent lipoprotein receptors on hepatic membranes of dog, swine, and man. Apoprotein B, E, and apoprotein E receptors. $J$. Clin. Invest. 68:1197-1206.

4. Mahley, R. W., and T. L. Innerarity. 1983. Lipoprotein receptors and cholesterol homeostasis. Biochim. Biophys. Acta. 737:197-222.

5. Pattnaik, N. M., A. Montes, L. B. Hughes, and D. B. Zilversmit. 1978. Cholesteryl ester exchange protein in human plasma. Isolation and characterization. Biochim. Biophys. Acta. 530:428-438.

6. Chajek, T., and C. J. Fielding. 1978. Isolation and characterization of a human serum cholesterol ester transfer protein. Proc. Natl. Acad. Sci. USA. 75:3445-3449.

7. Ihm, I., J. L. Ellsworth, B. Chataing, and J. A. K. Harmony. 1982. Plasma protein-facilitated coupled exchange of phosphatidylcholine and cholesteryl ester in the absence of cholesterol esterification. J. Biol. Chem. 257:4818-4827.

8. Albers, J. J., J. H. Tollefson, C. Chen, and A. Steinmetz. 1984. Isolation and characterization of human plasma lipid transfer proteins. Arteriosclerosis. 4:49-58.

9. Morton, R. E., and D. B. Zilversmit. 1982. Purification and characterization of lipid transfer protein(s) from human lipoprotein-deficient plasma. J. Lipid Res. 23:1058-1067.

10. Tall, A. R., E. Abreu, and J. Shuman. 1983. Separation of a plasma phospholipid transfer protein from cholesterol ester/phospholipid exchange protein. J. Biol. Chem. 258:2174-2180.

11. Abbey, M., S. Bastiras, and G. D. Calvert. 1985. Immunoprecipitation of lipid transfer protein activity by an antibody against human plasma lipid transfer protein-I. Biochim. Biophys. Acta. 833:25-33.

12. Morton, R. E., and D. B. Zilversmit. 1983. Inter-relationship of lipids transferred by the lipid-transfer protein isolated from human lipoprotein-deficient plasma. J. Biol. Chem. 258:11751-11757.

13. Tall, A. R., D. Sammett, G. Vita, R. J. Deckelbaum, and T. 
Olivecrona. 1984. Lipoprotein lipase enhances the cholesteryl ester transfer protein-mediated transfer of cholesteryl esters from high density lipoproteins to very low density lipoproteins. J. Biol. Chem. 259:95879594.

14. Sammett, D., and A. R. Tall. 1985. Mechanisms of enhancement of cholesteryl ester transfer protein activity by lipolysis. J. Biol. Chem. 260:6687-6697.

15. Chajek, T., and S. Eisenberg. 1978. Very low density lipoproteins. Metabolism of phospholipids, cholesterol, and apolipoprotein $\mathrm{C}$ in the isolated perfused rat heart. J. Clin. Invest. 62:1654-1665.

16. Patsch, J. M., A. M. Gotto, T. Olivecrona, and S. Eisenberg. Formation of high density lipoprotein ${ }_{2}$-like particles during lipolysis of very low density lipoproteins in vivo. Proc. Natl. Acad. Sci. USA. 75: 4519-4523.

17. Tall, A. R., P. H. R. Green, R. M. Glickman, and J. W. Riley. 1979. Metabolic fate of chylomicron phospholipids and apoproteins in the rat. J. Clin. Invest. 64:977-989.

18. Redgrave, T. G., and D. M. Small. 1979. Quantitation of the transfer of surface phospholipids of chylomicrons to the high density lipoprotein fraction during the catabolism of chylomicrons. J. Clin. Invest. 64:162-171.

19. Havel, R. J., J. P. Kane, and M. L. Kashyap. 1973. Interchange of apolipoproteins between chylomicrons and high density lipoproteins during alimentary lipemia in man. J. Clin. Invest. 52:32-38.

20. Tall, A. R., C. B. Blum, G. P. Forester, and C. Nelson. 1982. Changes in the distribution and composition of plasma high density lipoproteins after ingestion of fat. J. Biol. Chem. 257:198-207.

21. Castro, G. R., and C. J. Fielding. 1985. Effects of postprandial lipemia on plasma cholesterol metabolism. J. Clin. Invest. 75:874-882.

22. Tall, A. R., and P. H. R. Green. 1981. Incorporation of phosphatidylcholine into spherical and discoidal lipoproteins during incubation of egg phosphatidylcholine vesicles with isolated high density lipoproteins or with plasma. J. Biol. Chem. 256:2035-2044.

23. Fielding, P. E., C. J. Fielding, R. J. Havel, J. P. Kane, and P. Tun. 1983. Cholesterol net transport, esterification, and transfer in human hyperlipidemic plasma. J. Clin. Invest. 71:449-460.

24. Allain, C. C., L. S. Poon, C. S. G. Chan, W. Richmond, and P. C. Fu. 1974. Enzymatic determination of total serum cholesterol. Clin. Chem. 20:470-475.

25. Steele, B. W., D. F. Koehler, M. M. Azar, T. P. Blaszkowski, K. Kuba, and M. E. Dempsey. 1976. Enzymatic determinations of choles- terol in high density lipoprotein fractions prepared by a precipitation technique. Clin. Chem. 22:98-101.

26. Pattnaik, N. M., and D. B. Zilversmit. 1979. Interaction of cholesteryl ester exchange protein with human plasma lipoproteins and phospholipid vesicles. J. Biol. Chem. 254:2782-2786.

27. McVicar, J. P., S. T. Kunitake, R. L. Hamilton, and J. P. Kane. 1984. Characteristics of human lipoproteins isolated by selected-affinity immunosorption of apolipoprotein A-I. Proc. Natl. Acad. Sci. USA. 81: 1356-1360.

28. Cheung, M. D., and J. J. Albers. 1984. Characterization of lipoprotein particles isolated by immunoaffinity chromatography. J. Biol. Chem. 259:12201-12209.

29. Rose, H. G., and J. Juliano. 1979. Regulation of plasma lecithin: cholesterol acyltransferase in man. III. Role of high density lipoprotein cholesteryl esters in the activating effect of a high-fat test meal. J. Lipid Res. 20:399-407.

30. Dole, V. P. 1956. A relation between nonesterified fatty acids in plasma and the metabolism of glucose. J. Clin. Invest. 35:150-154.

31. Ihm, J., D. M. Quinn, S. J. Bosch, B. Chataing, and J. A. K. Harmony. 1982. Kinetics of plasma protein-catalyzed exchange of phosphatidylcholine and cholesteryl ester between plasma lipoproteins. $J$. Lipid Res. 23:1328-1341.

32. Sniderman, A., B. Teng, C. Vezina, and Y. L. Marcel. 1978. Cholesteryl ester exchange between human plasma high and low density lipoproteins mediated by a plasma protein factor. Atherosclerosis. 31: 327-333.

33. Eisenberg, S. 1985. Preferential enrichment of large-sized very low density lipoprotein populations with transferred cholesteryl esters. J. Lipid Res. 26:487-494.

34. Barter, P. J., G. J. Hopkins, and L. Gorjatschko. 1984. Comparison of human plasma low- and high-density lipoproteins as substrates for lecithin:cholesterol acyltransferase. Biochim. Biophys. Acta. 792:1-5.

35. Patsch, J. R., S. Prasad, A. M. Gotto, and G. Gentsson-Olivecrona. 1984. Postprandial lipemia. A key for the conversion of high density lipoprotein into high density lipoprotein $_{3}$ by hepatic lipase. J. Clin. Invest. 74:2017-2023.

36. Patsch, J. R., J. B. Karlin, L. W. Scott, L. C. Smith, and A. M. Gotto. 1983. Inverse relationship between blood levels of high density lipoprotein subfraction 2 and magnitude of postprandial lipemia. Proc. Natl. Acad. Sci. USA. 80:1449-1453. 